\title{
Identification of Locally Isolated Clostridium difficile from Rabbits
}

\author{
Medhat M Taha, Hamed A El-Helw, Elham F. El-Sergany, Hala El Sawy, Yasser A Abdella and Alaa A El-Meneisy \\ Department of Anaerobic Bacterial Research, Serum and Vaccine Research Institute, Abbassia, Egypt \\ *Corresponding author`s Email: medhattaha@hotmail.com
}

\begin{abstract}
Clostridium difficile is one of the most important pathogens causing diarrhea and enteritis in rabbits as it causes pseudomembranous colitis that leads to intestinal damage and deaths. In this study, screening of rabbit farms from different localities in Egypt had shown rabbits suffered from diarrhea and enteritis to detect Clostridium difficile by ELISA, it revealed that five out of 50 samples (10\%) were positive for it. These samples were further identification by cultivation and culture characters, microscopical examination, agglutination test, pathogenicity test and Polymerase Chain Reaction (PCR) by using specific primers for toxins genes (tcdA and tcdB). The results showing that three out of five isolates were confirmed as Clostridium difficile and concluded that these isolates causing pseudomembranous enterocolitis in rabbits and this disease unable to be treated by antibiotics, so it used for preparation of vaccine against the disease in rabbits.
\end{abstract}

Keywords: Clostridiunm difficile, Rabbits, Enteritis

\section{INTRODUCTION}

There is a strong and continuing interest in the development of rabbit industry in Egypt. Rabbit industry as one of the small livestock has a unique commercial role in solving the shortage in the meat after poultry industry (Mohamed et al., 2013). To achieve this purpose a special light should be thrown on dangerous rabbit diseases which may affect the industry. Enteritis complex is one of the important causes of disease and economic losses in younger rabbits. Many causes lead to enteritis and can result in health problems for the rabbit (Songer, 1996).

Clostridia species are the cause in the induction of enteritis problem in rabbits with high occurrence percentages (Hong et al., 2017). Different types of Clostridial species found in weaned rabbit farms at Egyptian governorates. Clostridial enterotoxaemia refers to enteritis caused by toxogenic microorganism of the genus Clostridium which characterized by diarrhea and may be sudden death. The main etiological agentsare Clostridium Perfringens; Clostridium spiroforme; Clostridium Butyricum, and Clostridium difficile (Khalefa et al., 2012; El-Helw et al., 2014)

Clostridium difficile ( $C$. difficile) is a gram positive, spore forming,anaerobic, toxin producing bacillus, catalase negative bacterium (Bruce et al., 1999). Pathogenic strains of C.difficle produce two potent toxins, enterotoxin A and cytotoxin $\mathrm{B}$, these toxins are the virulence factors of the organism and thereisa global problem which caused by ingestion of vegetative organisms and spores, most likely the latter which survive exposure to gastric acidity and germinate in the colon (Doosti and Mokhtari, 2014). C. difficile recognized as a major nosocomial pathogen responsible for antibiotic related diarrhea and is etiological agent of perforation of the colon, pseudomembranous colitis or toxic megacolon and even death in humans (Hung et al., 2012). C. difficile also is an important factor for enteric disease in other species; it cause enterocloitis associated with diarrhea in horses specially foals (Taha, 2014), it cause chronic diarrhea in dogs (Andrea et al., 1994), and had been isolated from calves, pigs, rabbits and cats (Rodriguez Palacios et al., 2006). In rabbits, cases of clostridiosis caused by $C$. difficile have been reported from 35 to 55 days of age, in which enteroclitis with liquid caecal content was observed. $C$. difficile was first isolated from faeces of four often healthy newborn infants in 1935; it was named Bacillus difficilis because of difficulty in isolating and studying these bacteria. (Hall and O'Toole, 1935)

The aim of this study is to isolate and identify $C$. Difficile and confirm it as a causative bacterial agent of diarrhea from naturally infected rabbits and as a primarily step for preparation of vaccine from locally isolated strain.

\section{MATERIALS AND METHODS}

Ethical approval

All procedures performed according to Egyptian ethical standards of the National Research Committee. 


\section{Screening for detection of $C$. difficile infection in rabbits}

Fifty rabbits aged between one to four months were recently dead where suffered from abdominal distension and diarrhoea, obtained from different farms in Egypt. Screening was done by using RIDASCREEN ${ }^{\circledR}$ C. difficile toxin A/B kit (R-Biopharm AG, Dermstadt, Germany). This Kit using monoclonal antibodies against C.difficile toxins A and B used as screening test for detection of $C$. difficile toxins. Faecal and ceacal samples (approx. 100 $\mu$ l) were aspirated and $1 \mathrm{ml}$ RIDASCREEN ${ }^{\circledR}$ C . difficile sample dilution buffer were added, samples were homogenized, blend in votex mixer, suspension left stand a short period of time for the coarse stool particles to settle, and clarified supernatant of samples suspension used in the test. The assay was done according to procedure of ELISA Kit manual. The optical density of samples; positive, and negative control were recorded after reading by ELISA reader. Calculation the cut-off for the negative control, an assessment of specimen as positive if extinction rate is more than $10 \%$ higher than calculated cut-off value.

\section{Isolation of the causative agent}

Positive faecal samples and/or caecal contents from rabbits were collected and alcohol shocked is used (Saverio and Pauline, 1980), then pellets were inoculated on C. difficileagar base (CM0601, Oxoid LTD, England) with $C$. difficile selective supplement (SR0096E, Oxoid LTD, England) and incubated for 48 hours anaerobically at $37{ }^{\circ} \mathrm{C}$ (Saverio and Pauline, 1980). Suspected colonies were harvested and stained with Gram stain. Microscopical examination, culture characters (culture morphology, odour and effect of long wave length ultraviolet) and biochemical tests (catalase and oxidase tests) were carried out (Hafiz and Oakely, 1976).

\section{Clostridium difficile agglutination test}

Clostridium difficile latex agglutination kit (Oxoid Ltd. DR1107, England) where used for detection of C. difficile. A loopful from the suspected colonies, positive control provided (C.difficile cell wall antigen) and negative control (0.85 $\%$ isotonic saline) were tested using the specific reagent provided (latex particle coated with IgG antibodies specific for C. difficile cells wall antigen) on a reaction card, latex particles agglutinate in large visible clumps within two minutes in positive control as well as in positive samples (Kelly et al., 1987).

\section{Pathogenicity test}

Selected colonies were suspended in $1 \%$ peptone saline, and then was adjusted to $9 \times 10^{10}$ cells $/ \mathrm{ml}$, and inoculated intramuscularly in each of three rabbits aged between 30-40 days. The isolation of organism was done again (Hutton et al., 2014).

\section{Toxin preparation}

Thioglycollate broth with $1 \%$ glucose was prepared and seeded with C.difficile suspected colonies and incubated anaerobically for $72 \mathrm{~h}$, the supernatant collected after centrifugation at $3500 \mathrm{rpm}$ for $30 \mathrm{~min}$ then filtered with Seitz filter and the toxognecity test was done by injecting the prepared crude toxin $0.2 \mathrm{ml} \mathrm{IV} \mathrm{(intravenous)} \mathrm{and} \mathrm{its} \mathrm{three} \mathrm{double} \mathrm{fold}$ dilution in three mice each $(0.2 \mathrm{ml} / \mathrm{IV} /$ mice) to investigate the minimum lethal dose (MLibby et al., 1982).

\section{Polymerase Chain Reaction}

DNA was extracted from the suspected colony of the positive samples transferred into a $0.6-\mathrm{mL}$ microcentrifuge tube containing $100 \mu \mathrm{l}$ of sterile water and was boiled at $100^{\circ} \mathrm{C}$ for $10 \mathrm{~min}$. After boiling, the sample was centrifuged at low speed $(3000 \mathrm{rpm})$ to remove cell debris. The supernatant containing the DNA was used for amplification reactions (Perkins et al., 1995). Toxin A and B genes were amplified as described (Stuart et al., 2000) and the sequences of the primers used shown in table 1.

\section{RESULTS}

Infected rabbits showed abdominal distension and diarrhea as in figure 1. Specific ELISA kit was used for detection of Clostridium difficile toxin $\mathrm{A} / \mathrm{B}$ for the 50 faecal samples and caecal contents and the obtained results confirm 5 positive samples representing $10 \%$ of tested samples, table 2 .

Isolation of the positive faecal and caecal samples on specific medium revealed greyish regular smooth colonies (Figure 2) with manure characteristic odour, and the gram stain of the suspected colonies showed gram positive bacilli as in figure 3 revealed. These obtained agreed with authors who stated that $C$. difficile colonies on blood agar were greyish in colour with characteristic distinctive manure odour, and the organism is gram positive rod measuring $0.5 \mathrm{X} 3-6$ um (Mohamed et al., 2013). The isolated colonies produce a pale green fluorescence under long wave length ultraviolet as shown in figure 4. Furthermore, ELISA was done using RIDASCREEN® C. difficile Toxin A/B kit (R-Biopharm, Germany) as shown in table 2. 
Table 1. Sequence of the primers used for polymerase chain reaction of the isolates designed for Clostridium difficile

\begin{tabular}{|c|c|c|c|}
\hline $\begin{array}{l}\text { Gene } \\
\text { target }\end{array}$ & Primer Name & Sequence $(5-3)$ & Amplicon size (bp) \\
\hline \multirow{2}{*}{$\operatorname{tcd} \mathrm{A}$} & F-YT-28 & GCATGATAAGGCAACTTCAGTGG & \multirow{2}{*}{602} \\
\hline & R-YT-29 & GAGTAAGTTCCTCCTGCTCCATCAA & \\
\hline \multirow{2}{*}{$\operatorname{tcd} \mathrm{B}$} & F-YT-17 & GGTGGAGCTGCTTCATTGGAGAG & \multirow{2}{*}{399} \\
\hline & R-YT-18 & GTGTAACCTACTTTCATAACACCA & \\
\hline
\end{tabular}

Table 2. Optical Density readings at $450 \mathrm{~nm}$ wave length five positive samples from the fifty infected rabbits Clostridium difficile, 2018 in Egypt

\begin{tabular}{cc}
\hline Samples & Mean of O.D.(Absorbance) \\
\hline 1 & $0.465 \pm$ \\
2 & $0.785 \pm$ \\
3 & $0.692 \pm$ \\
4 & $0.474 \pm$ \\
5 & 0.545 \\
Negative control & $0.128 \pm$ \\
Positive control & $1.242 \pm$ \\
Cut-off (negative control+0.15) & 0.278 \\
\hline
\end{tabular}

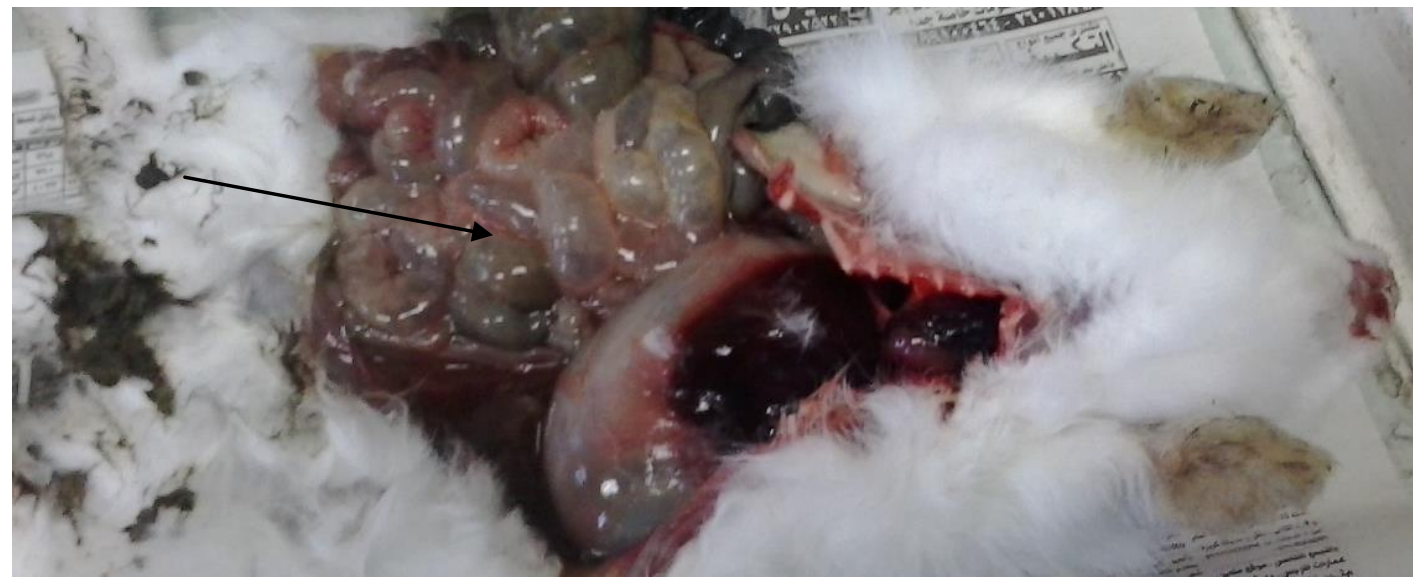

Figure 1. Abdominal distension in rabbits infected with Clostridium difficile

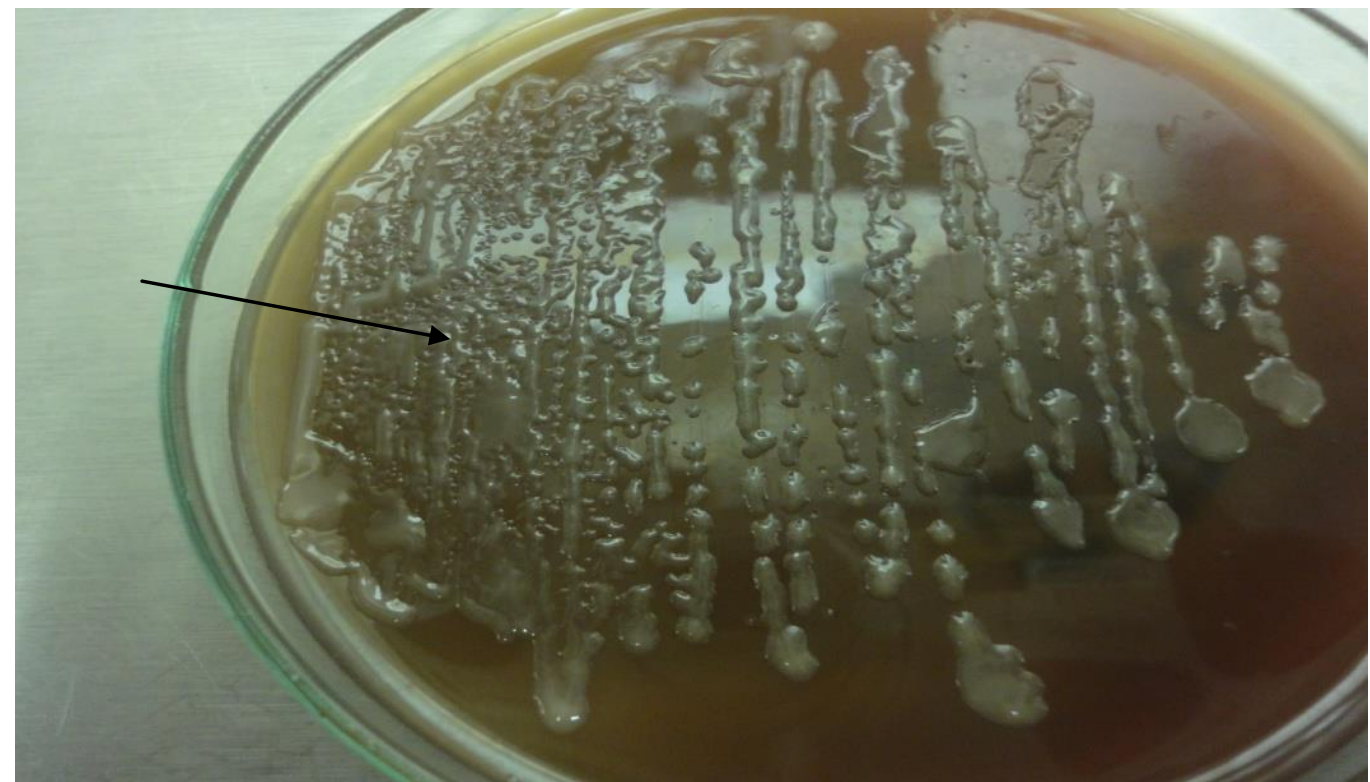

Figure 2. Suspected colonies of Clostridium difficile after cultivation on the specific medium 


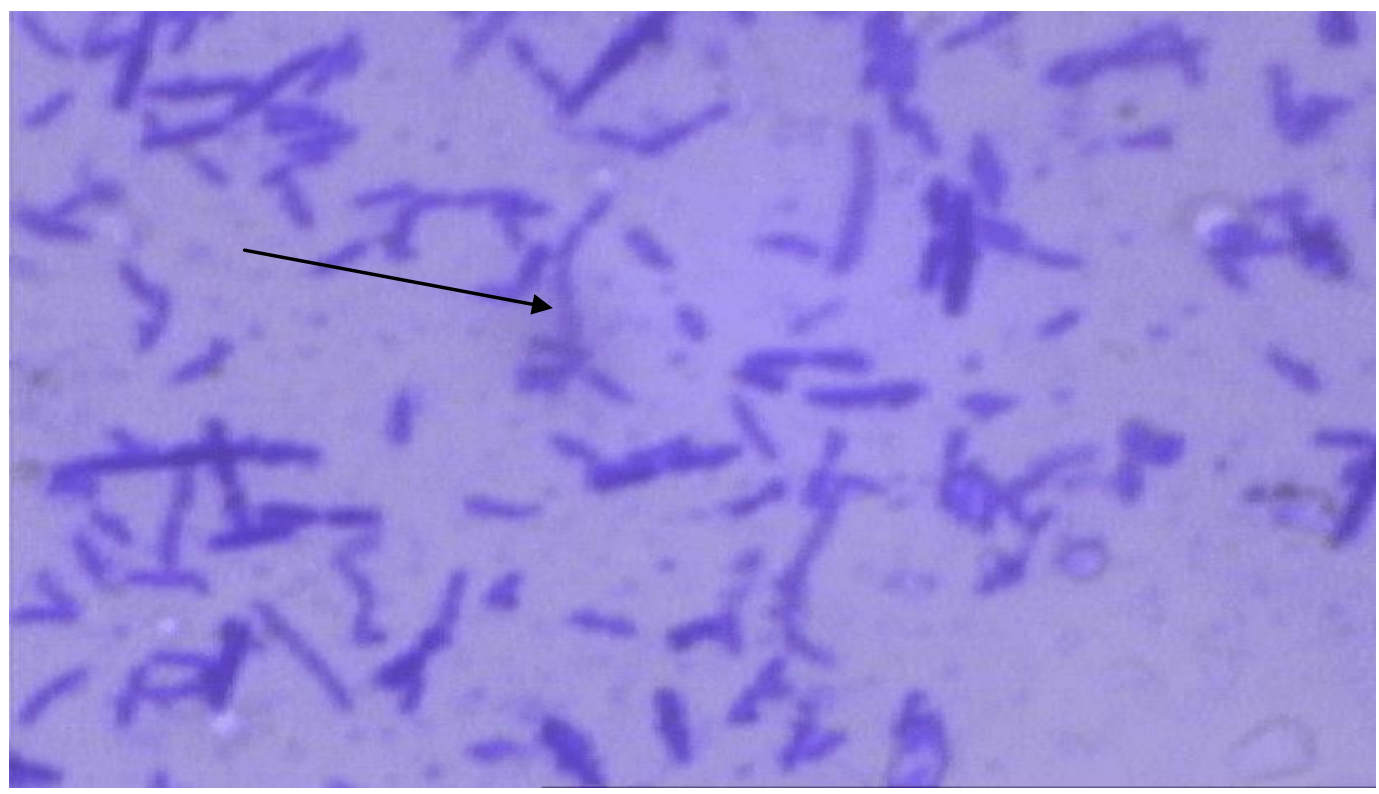

Figure 3. Gram stain of the suspected colonies from the specific agar medium

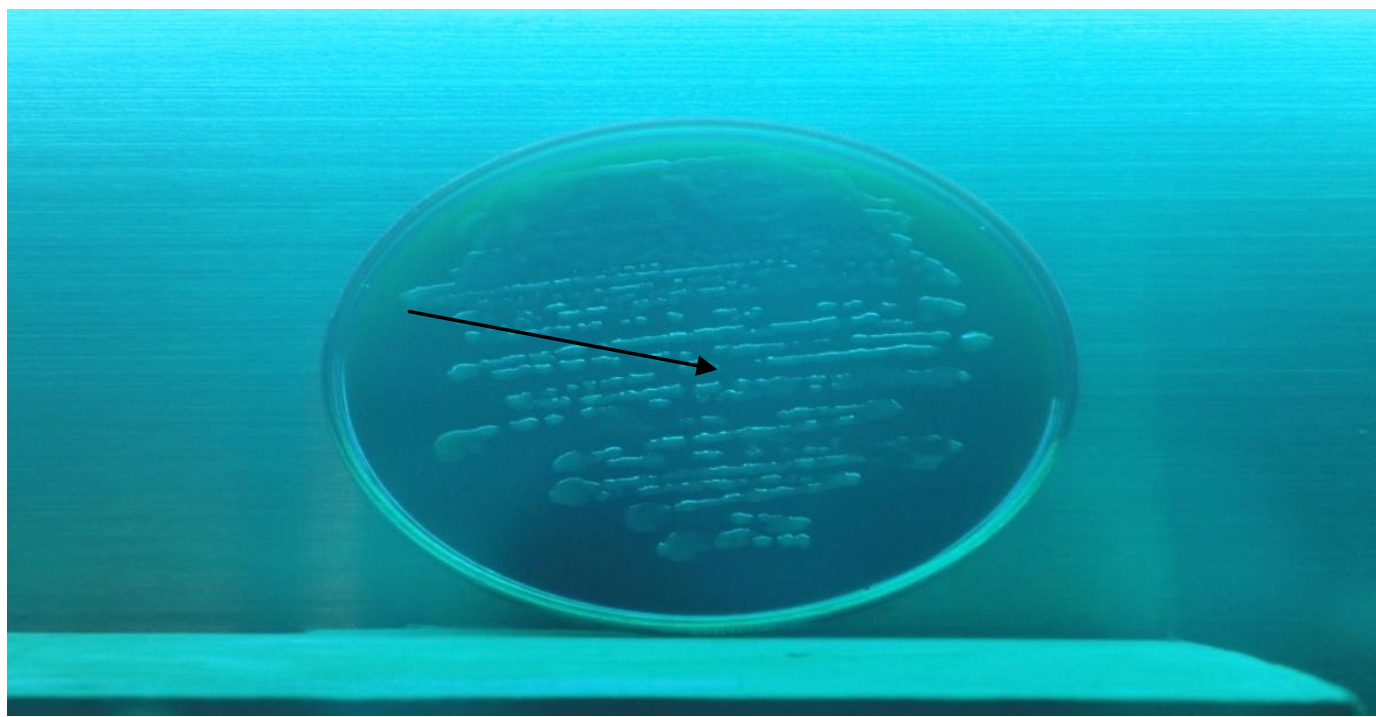

Figure 4. Pale green fluorescence colonies under long wave

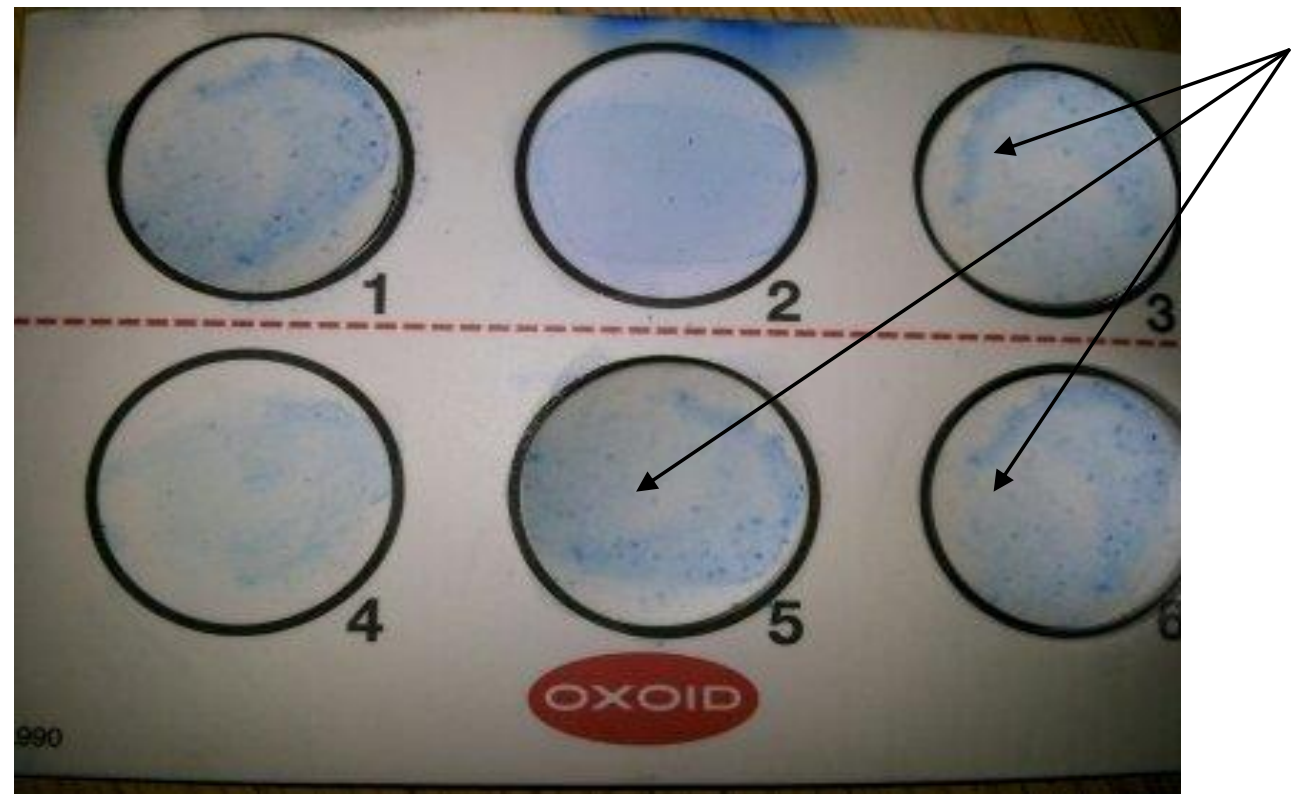

Figure 5. Latex agglutination test using the isolated Clostridium difficile. 1: positive control, 2: negative control. 3, 5, 6: positive samples and 4: negative samples 


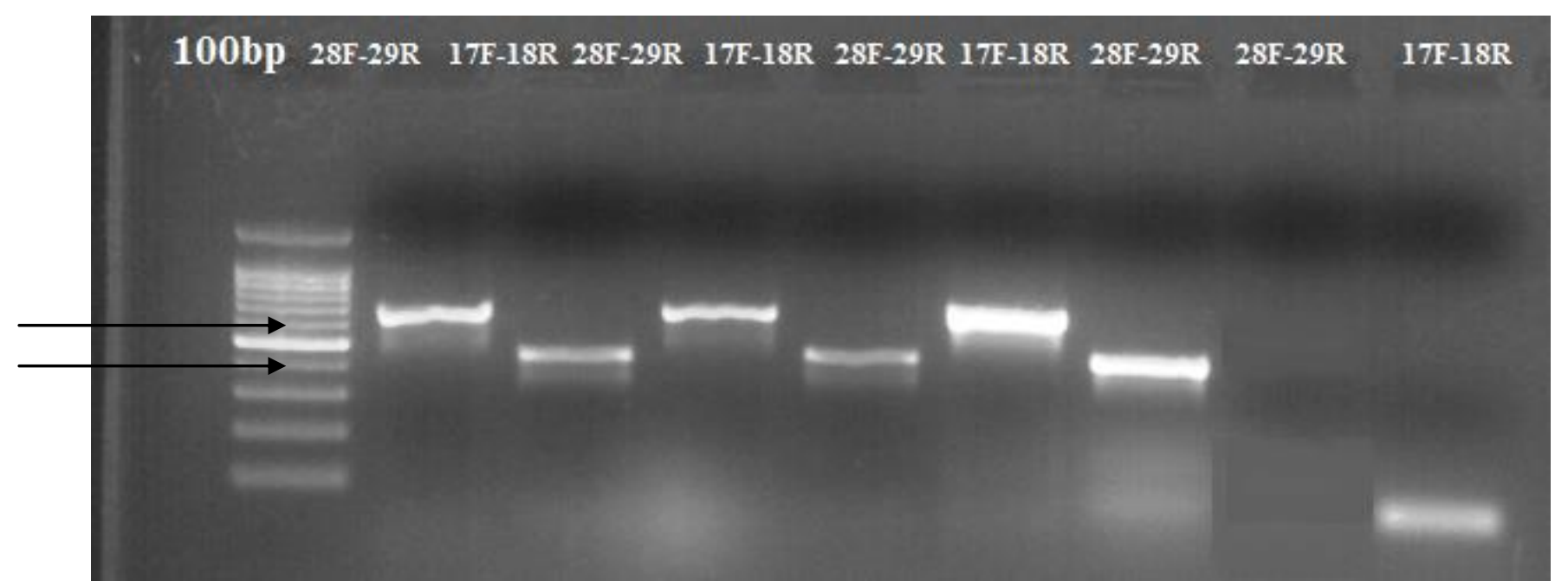

Figure 6. Polymerase chain reaction for the isolates of Clostridium difficile for tcdA and tcdB genes lane 1 :molecular markers 100-1000, lanes 2,4,6,8: for the four isolates with tcd A gene, lanes 3,5,7,9: the four isolates with gene tcd B, 2018

\section{DISCUSSION}

Clostridium difficile is a confirmed pathogen in a wide variety of mammals, but the incidence of disease varies greatly in relation to host species, age, environmental density of spores, administration of antibiotics, and possibly of other factors. Lesions vary as well, in severity and distribution within individuals, and in some instances, age groups, of a given species. The cecum and colon are principally affected in most species, but foals and rabbits develop severe jejunal lesions (Keel and Songer, 2006).

C. difficile is usually a harmless environmental bacterium and the normal intestinal microflora has to be disturbed before $C$. difficile can become established and produce its toxins. There is an initial disruption of the normal colonic bacterial floraby antibiotic treatment, allowing $C$. difficile from endogenous or exogenous origins to express itself in the colon then proliferate and produce toxins A and B simultaneously, these protein toxins bind to specific receptors on the luminal aspect of colonic epithelium transported to the cytoplasm by receptor mediated endocytosis. Thus, $C$. difficile toxins cause themucosal injury in the colon as a result damage to the cytoskeleton and inhibition of the functioning of tight junctions and cause fluid secretion, inflammation and mucosal damage, which by its turn lead to diarrhea and psudomembranous colitis.

The isolates gave catalase negative using hydrogen peroxide (as no bubbles of liberated oxygen formed)and oxidase negative when tetramethyl-p-phenylendiamne added where no change in colour occurred, these results agreed with those who reported that $C$. difficile is catalase and oxidase negative (Perkins et al., 1995). C. difficile latex agglutination test for the colonies revealed 3 positive samples out from five samples, in comparing to the positive and negative controls provided as shown in figure 5. ELISA done revealed three positive sample as recorded in table 2. Toxin A/B was prepared from one of the positive colonies and inoculated IV in two mice each, the four mice (two of the toxins as it is and two with double fold dilution. of the toxin) were all dead within 48 hours which revealed that the isolated colony is toxogenic.

PCR results using tcdA and tcdB genes primers as showed in figure 6, revealed that bands at $602 \mathrm{bp}$ and $399 \mathrm{bp}$ respectively for three positive samples, while other sample was negative for both genes ,that agreed completely with (Stuart et al., 2000) who detected four positive samples using PCR for the genes of toxins A and B from 10 samples. Also authors stated that $62 \%$ of samples revealed positive samples for C.difficile using multiplex PCR and they stated that tcdA and tcdB genes confirmed that isolate is toxogenic (Leond et al., 2000).

\section{CONCLUSION}

All the results obtained from present study indicated that $C$. difficile which have been isolated is toxogenic and could be used for production of vaccine against pseudomembranous colitis in rabbits which in turn help the rabbit industry by providing the specific vaccine.

\section{DECLARATIONS}

\section{Author's contribution}

TMM and EHA isolate Clostridium difficile from infected rabbits and perform ELISA, EFE contributes agglutination test HES and YAA perform PCR for the isolated C. difficile and AAE provide the infected rabbits from the farms. 


\section{Consent to publish}

The author(s) grant(s) the publisher the sole and exclusive license of the full copyright in the contribution. Consequently, the publisher shall have the exclusive right throughout the world to publish and sell the contribution in all languages and all other forms of electronic publication now known or hereinafter invented.

\section{Competing interests}

All authors have no conflict of interest.

\section{REFERENCES}

Cohen SH, Tang YJ and Joseph Silva JR (2000). Analysis of the pathogenicity Locus in Clostridium difficile strains. Journal of Infectious Disease, 181(2): 659-664.

Doosti A and Mokhtari F (2014). Study of the frequency of $C$. difficiletcdA, tcdB, cdtA and cdtB genes in faeces of calves in south west of Iran. Annals of Clinical Microbiology and Antimicrobials, 13:21.

El Helw HA, Abdella YA,Elham F, Taha MM and El Meneisy AA (2014). Isolation and identification of C. butyricum as a causative agent of necrotizing enterocolitis in rabbits. Minufiya Veterinary Journal, 8(1): 23-32.

Hafiz S and Oakely CL (1976). Clostridium difficile, Isolation and characteristics. Journal of Medical Microbiology, 9:129136.

Hall IC and O`Toole E (1935). Intestinal flora in newborn infants with a description of a new pathogenic anaerobe, Bacillus difficilis. American Journal of Disease of Children, 49: 390-402.

Hong HA, Hitri K, Kotowicz SN, Bryan D, Mawas F, Wilkinson AJ, Broekhoven AV, Kearsey J and Cuttin SM (2017). Mucosal Antibodies to the C Terminus of Toxin A Prevent Colonization of Clostridium difficile, Infection and Immunity, 8(4): 2-13. Doi: 10.1128/IAI.00279-17

Hung YP, Tsai P, Hung KH, Liu HC, Lee CL, Lin HJ, Wu YH and Ko WC (2012).

Impact of toxogenic $C$. difficile colonization and infection among hospitalized adults at Destrict Hospital in Southern Taiwan. PLoS One, 7(8): e42415. Doi: 10.1371/journal.pone.0042415.

Hutton ML, EMackin K, Chakravorty A and Lyras D (2014). Small animals models for the study of C. difficile diseases pathogenesis. FEMS Microbiology Lett, 352: 140-149.

Keel MK and Songer JG (2006). The comparative pathology of Clostridium difficile associated disease. Veterinary Pathology, 43: $225-240$

Kelly MT, Champagne SG, Sherlock CH, Noble MA, Freeman HJ and Smith AJ (1987). Commercial latex agglutination test for detection of $C$. difficile associated diarrhea. Journal of Clinical Microbiology, 25(7): 1244-1247.

Khelfa DEDG, Wafaa AAE-G, Alem HM and Khelfa DEDG (2012). Recent status of Clostridial enteritis affecting early weaned rabbits in Egypt. Life science Journal, 9(4): 2272-2279.

Leond T, Natalia L, Alexander S, Yajarayama J, Stuart H and Joseph J (2000). Isolation and Molecular characterization of Clostridium difficile strains from patients and the hospital environment in Belarus. Journal of Clinical Microbiology, 38(3): 1200-1202.

Madewell BR, Bea JK, Kraegel SA, Winthrop M, Tang YJ and Silva JJr (1999). Clostridium difficile;a survey of fecal carriage in cats in a veterinary medical teaching hospital. Journal of Veterinary Diagnostic Investment, 11:50- 54. Doi: https://doi.org/10.1177/104063879901100108

MLibby J, Jortner BS and DWilkins T (1982). Effects of the two toxins of $C$. difficile in antibiotic associated cecitis in Hamster. Infection and Immunity, May, 822-829. Doi: 10.1258/la.2008.008072

Mohamed HA, Eid AAM and El Bakery RMM (2013). A review of rabbit disease in Egypt. Wartazoa, Vol. 23 No. 4 Th. 2013

Perkins SE, Fox JG, Taylor NS, Green DL and Lipman NS (1995). Detection of Clostridium difficile toxins from the small intestine and caecum of rabbits with naturally acquired enterotoxaemia. Laboratory Animal Science, 45: 379-384.

Rodriguez Palacios A, Stampfl HR, Duffield T, Peregrine AS, Trotz Williams A, Arroyso LG, Brazier JS and Weese JS (2006). Clostridium difficile PCR Ribotypes in claves. Emerging Infectious Disease, 12: 1730-1736.

Saverio PB and Pauline H (1980). Simplified procedure for the routine isolation of Clostridium difficile from faeces. Journal of Clinical Pathology, 34:1124-1127.

Songer JG (1996). Clostridial enteric diseases of domestic animals. Clinical Microbiology Review, 9:216-234.

Struble AL, Tang YJ, Kass PH, Gumerlock PH, Madewell BR and Silva JJr (1994).

Fecal shedding of $C$. difficile in dogs: A period prevalence survey in a veterinary medical teaching hospital. Journal of Veterinary investigation, 6:324-347. Doi: 10.1177/104063879400600310 
Taha MM (2014). Isolation and identification of C. difficile from horses. Zagazig Veterinary Journal, 42(2): 124-130. 